\title{
Media Richness, Communication Apprehension and Participation in Group Videoconferencing
}

\author{
John Campbell \\ University of Canberra, Canberra, ACT, Australia
}

john.campbell@canberra.edu.au

\begin{abstract}
Although videoconferencing technologies perform an important function in organizational communication, many users remain apprehensive about using the medium for routine communication. The study draws on media choice theory to assess the impact of communication apprehension and participation on perceptions of task characteristics and media traits. The results demonstrate that user aversion to videoconferencing has a significant impact on perceptions of task and media. A significant interaction was also revealed between communication apprehension and user participation relating to perceptions of communication richness.
\end{abstract}

Keywords: communication apprehension, media characteristics, media selection, organizational communication, task traits, videoconferencing.

\section{Introduction}

Many users are not comfortable with their performance when using communication technologies such as videoconferencing (Scott \& Rockwell, 1997). A popular view is that these people are apprehensive about using communication technologies because they have little understanding of the technologies or how to use them effectively (Booth-Butterfield \& Cattone, 1991; Martinsons \& Chong, 1999). This uneasiness is an important consideration concerning the effective use of organizational communication technologies (Okebukola, Sumampouw, \& Jegede, 1992). User apprehension is one factor generally overlooked when assessing the effectiveness of new communication technologies. Prior research shows that communication apprehension can be a powerful inhibitor of an individual's involvement in communication activities particularly in technology mediated environments (Brown, Fuller, \& Vician, 2004; Easton, Easton, \& Belch, 2003; Rao \& Dennis, 2000; Richmond \& McCroskey, 1992; Scott \& Timmerman, 2005).

Communication apprehension is a fear or anxiety about actual or anticipated communication with other individuals, and is a behavioral trait related to the psychological constructs of shyness and reticence (McCroskey, 1984). Communication apprehensive individuals usually adopt avoidance and withdrawal behavior and are therefore less likely to engage in oral communication (Scott \&

Material published as part of this journal, either on-line or in print, is copyrighted by the Informing Science Institute. Permission to make digital or paper copy of part or all of these works for personal or classroom use is granted without fee provided that the copies are not made or distributed for profit or commercial advantage AND that copies 1) bear this notice in full and 2) give the full citation on the first page. It is permissible to abstract these works so long as credit is given. To copy in all other cases or to republish or to post on a server or to redistribute to lists requires specific permission and payment of a fee. Contact Publisher@InformingScience.org to request redistribution permission.
Rockwell, 1997). Hence, communication apprehension will be more acute when using communication technologies that center on oral communication such as in audio and videoconferencing. However, unlike the users of other oral communication technologies, videoconferencing participants are more acutely aware of their self-image and of the potential for the system to portray a less than favorable image to others (Storck 
\& Sproull, 1995; Webster \& Hackley, 1997). This phenomenon is of particular concern as the managerial use of videoconferencing is increasing rapidly as organizations become more global in focus and less hierarchical in structure (Hart, Svenning, \& Ruchinskas, 1995; Kydd \& Ferry, 1994).

\section{Theoretical Background}

\section{User Apprehension and Participation}

User aversion to new technologies is often viewed as a systems analysis and design issue that is best addressed at the system implementation stage through participation in practice sessions and formal training (Lee \& Bohlen, 1997; Lucas, 1978). This perspective assumes that the anxiety and apprehension are removed once users are sufficiently desensitized to using the technology. This view is supported by empirical evidence concerning user acceptance of microcomputer technologies (Igbaria, 1993). However, there is evidence that experience alone does not totally alleviate communication apprehension as individuals may also be averse to the communication task in addition to the communication technology (Rosen, Sears, \& Weil, 1993; Weil, Rosen, \& Wugalter, 1990). The literature reports that these anxious users tend to be less self-confident, display poor cognitive processes, and are perceived by other participants as inattentive and poor communicators (Allen \& Bourhis, 1996).

User apprehension towards communication technology may significantly reduce individual and organizational effectiveness. This aversion could create dysfunctional communication patterns with significant performance costs for organizations and detrimental career implications for individuals (Okebukola et al., 1992; Scott \& Rockwell, 1997). Managers also need to be aware of the difficulties caused by user discomfort as user apprehension plays a critical role in the success of new technologies. Unfortunately, the literature focuses on the causes of anxiety rather than its effect on communication and performance so little is known about the actual impacts.

User apprehension and discomfort connected with participation in videoconferencing are important aspects of privacy theories (Storck \& Sproull, 1995; Webster, 1998). The literature suggests that user apprehension and anxiety about using a technology is partly caused by the heightened level of self-awareness felt by many users and can lead to less confident communicators (Stone \& Stone, 1990). When using communication technologies, users consistently report a strong concern for dignity and the respect of their peers. Unlike other information technology applications that provide some degree of privacy and anonymity, participation in videoconferences can make some feel self-conscious about on-screen appearance and performance. This self-consciousness is often very noticeable and can be a significant impediment to effective communication.

\section{Task and Media Characteristics}

Videoconferences have been shown to differ from face-to-face meetings in (1) the level of conflict and misunderstanding; (2) the structure of meetings; (3) task focus - the number of interruptions and distractions during meetings; (4) problem complexity and the degree and frequency of group interaction; (5) sociability - the degree of social presence supported by the medium and (6) communication richness - how easily participants are able to develop a shared understanding and consensus (Campbell, 1997). Each of these factors reflects a different aspect of the media and task trait theories associated with the media selection literature (Carlson \& Davis, 1998). Meeting conflict, structure, task focus and problem complexity reflect different task characteristics while sociability and communication richness reflect different media traits. These factors are discussed in more detail in the following sub-sections. 


\section{Task characteristics}

Conflict is concerned with the incidence of misunderstandings, interjections and conflict between group members. There is considerable evidence in the literature that groups using electronic communication systems have more difficulty in achieving consensus than face-to-face groups (Dennis, George, Jessup, Nunamaker, \& Vogel, 1988; McGrath \& Hollingshead, 1993). Videoconferencing does not have the capacity to support meetings involving arbitration between conflicting viewpoints (McGrath, 1984). This has been confirmed in empirical studies that have examined the suitability of videoconferencing for different communication activities (Campbell, 1998; Kydd \& Ferry, 1994).

Meeting structure is concerned with the degree of structure enforced on meetings by the technology. It is believed that electronic meeting systems enhance participation by providing structure, allowing some processes to be performed in parallel, and preventing conflict and the domination of the group by a few individuals (Benbasat \& Lim, 1993; Konsynski, Stohr, \& McGee, 1992; McLeod, 1992). The structure imposed by videoconferencing technology also encourages better planning and preparation by participants (Campbell, 1997).

Task focus is concerned with the number of interruptions and distractions experienced during videoconferencing. While videoconferencing constrains interaction between participants and enforces structure, the same constraint also encourages greater task focus which can lead to higher quality outcomes and higher user satisfaction (Svenning \& Ruchinskas, 1984). During group videoconferencing there is an increase in meeting formality which reduces group tolerance of outside distractions and interruptions.

Problem complexity is concerned with the level of complexity that can be supported by videoconferencing including the depth and frequency of group interaction. Problem complexity relates to the level and depth of interaction required to solve the task at hand (McKeen \& Smith, 1996). The problem complexity aspects concerning videoconferencing relate to the scope and scale of the meetings, the number and diversity of meeting participants, meeting frequency, and the size of meeting agendas. As problem complexity increases, the inflexibility of videoconferencing systems causes meetings to become more difficult to manage.

\section{Media traits}

Sociability is concerned with the informal interaction between participants and is of central focus in the theories of media richness (Daft \& Lengel, 1984, 1986) and social presence (Short, Williams, \& Christie,, 1976). The social presence and media richness theories have provided important models that have been used to predict media choice and usage behaviors. Both perspectives recognize that sociability is an important factor in communication and that different communication media support different levels of social presence. The social presence facilitated by a communication medium is determined by user perceptions about the socio-emotional similarity of that medium to face-to-face conversation. There is a general consensus within the literature that as bandwidth narrows, the communications channel becomes less suitable for complex social interactions and interpersonal communication (Rice \& Williams, 1984). In videoconferencing, compared with face-to-face meeting environments, the feeling of contact or social presence is lessened and communication is likely to be described as less friendly, impersonal, business-like and task oriented (Rogers, 1986; Williams, 1978).

Communication richness is concerned with the ability to overcome misunderstandings and individual differences within videoconferenced meetings and to converge towards a shared understanding. Communication richness refers to the communication enactment processes that allow participants to develop the coherent and shared meaning necessary to complete the task at hand (Lee, 1994; Markus, 1994). Communication systems capable of supporting only lean information 
will inhibit the free flow of communication, reduce meeting effectiveness, and discourage participation. In videoconferences, the flow of information exchanges between participants is often slower and less spontaneous than in traditional meetings (Gowan \& Downs, 1994; Svenning \& Ruchinskas, 1984). Participants have consistently indicated that the cognitive workload is higher during videoconferences than for face-to-face meetings (O'Connaill, Whittaker, \& Wilbur, 1993).

\section{Method}

The success of videoconferencing systems are firmly linked to the attitude of users, and the emphasis on user perceptions in this study recognizes the sovereignty of user attitudes in determining system usage (Adams, Nelson, \& Todd, 1992; Davis, 1989). It is the attitude of users that provides the strongest indicator of system effectiveness and success (Guimaraes \& Dallow, 1999; Webster \& Trevino, 1995; Zmud, 1979).

The adoption of videoconferencing technology will vary depending, among other factors, on the culture and the communication norms within the organization. All groups will not adopt videoconferencing in like manner. The successful implementation and acceptance of videoconferencing technology will largely depend on how specific user groups interact with, change, or adopt the technology within their own unique workplace environments. Consequently, a survey was conducted using a sample of the in-house videoconferencing system users in the Brisbane office of a large Australian Federal Government agency. The agency has offices located in all Australian capital cities as well as in many of the major regional townships throughout the country. Videoconferencing has been deployed within the organization for almost 15 years and is a regularly used means of communication by distributed work teams. The most common activities used for videoconferencing include the communication of ideas, concepts and plans (McGrath, 1984). However, the medium is also sometimes used for planning and creative type collaborative activities.

Task and media traits were measured using a thirty-item instrument developed by Campbell (1997). Participation was measured by referring to actual system usage. Unlike many other information technology applications, participation in videoconferenced meetings is a conscious act that can be easily recalled with great accuracy. The simple measure used here was the number of videoconferenced meetings each user participated in during the four weeks preceding the survey. User apprehension was measured with a modified version of an instrument developed by Reinsch, Steele, Lewis, Stano, and Beswick (1990). The original instrument was designed to measure apprehension towards telephone usage but was easily adjusted to reflect a videoconferencing context.

\section{Analysis}

The survey instrument was distributed to the 125 office staff who had experience with the inhouse videoconferencing facilities. Eighty completed survey forms were returned, providing a 64 per cent response rate. All data were assessed for violations of the assumptions of multivariate analysis. Because of unacceptable skewness in the usage data (a skewness statistic greater than 3 standard errors), each survey response for this variable was re-coded to create a dichotomous variable reflecting whether the individual had participated in any videoconferencing session during the four weeks preceding the survey. The acceptance level for all tests was set at $p<.05$.

The apprehension scores were re-coded as a dichotomous variable using the median value to discriminate between the high and low apprehension respondents. This treatment provides clear contrast between the perceptions of the individuals in each group across the task characteristic and media trait variables. These perceptions can then be viewed as being dependent on the high/low apprehension classification and subsequently analyzed using a multiple analysis of variance ap- 
proach. While there will be some distortion with dichotomization, it has been argued that results generally remain robust for many statistical tests with little affect on Type I and Type II errors (Jaccard \& Wan, 1996).

\section{Results}

Over 60 per cent of respondents had one year or less experience and 45 per cent had not used the videoconferencing facilities during the four weeks preceding the survey. Approximately 64 per cent of respondents were male with a mean age of 38 years (over 57 per cent were aged between 31 and 45 years). The average length of employment with the organization was approximately nine years. More than 66 per cent of respondents reported a university level education and 55 per cent were middle management or professional staff. In summary, respondents were approaching middle age, had a considerable length of service with their present organization, and were well educated with the majority having a university degree. Organizational level, tenure, education and the age of respondents did not appear to have any influence on the level of participation and use of videoconferencing. However, respondents generally indicated a positive relationship between videoconferencing usage and personal standing in the organization. For example:

- Thirty-nine per cent indicated that videoconferencing provided an increase in personal visibility within the organization;

- Forty-three per cent reported that videoconferencing enabled greater access to key personnel; and

- Thirty-five per cent indicated that using videoconferencing provided a higher personal profile within the organization.

Correlations and factor reliabilities of all variables are displayed in Table 1. There are significant negative correlations between user apprehension and meeting structure, problem complexity, sociability and communication richness. However, there were no significant correlations between participation and any of the other study variables.

Table 1. Correlations and reliabilities for the study variables

\begin{tabular}{|c|c|c|c|c|c|c|c|c|c|}
\hline & Variables & 1 & 2 & 3 & 4 & 5 & 6 & 7 & 8 \\
\hline 1. & User apprehension & $(.96)$ & & & & & & & \\
\hline 2. & Participation & .16 & (NA) & & & & & & \\
\hline 3. & Conflict & -.02 & .20 & $(.67)$ & & & & & \\
\hline 4. & Meeting Structure & -.24 & -.11 & .04 & $(.78)$ & & & & \\
\hline 5 . & Task focus & -.21 & -.07 & .40 & .35 & $(.85)$ & & & \\
\hline 6. & Problem complexity & -.24 & -.14 & .23 & .48 & .51 & $(.73)$ & & \\
\hline 7. & Sociability & -.33 & .12 & .50 & .20 & .43 & .42 & $(.88)$ & \\
\hline 8. & Communication richness & -.55 & .05 & .23 & .50 & .40 & .56 & .63 & $(.91)$ \\
\hline
\end{tabular}

The results of the MANOVA tests are shown in Table 2. The results indicate that there is a multivariate main effect attributable to communication apprehension but not to participation. Univariate analyses were also performed between each of the categorical variables (apprehension and participation) and the task and media trait variables. For communication apprehension, perceptions of the high and low groups differed in their perceptions of problem complexity, task focus, sociability and communication richness. Not surprisingly, low apprehensive users viewed these aspects of videoconferenced meetings more favorably than their more apprehensive colleagues 
did. Interestingly, univariate tests between the level of participation and the task and media variables revealed that the more recent participants felt that videoconferenced meetings involved a higher level of conflict than face-to-face meetings.

The analysis uncovered a significant interaction between participation and communication apprehension. Univariate analysis revealed that recent participation in videoconferencing is linked to perceptions about communication richness. The communication richness values for different levels of participation and apprehension are presented in Figure 1. The graph indicates that the groups are differentially affected by the two conditions. Regular use by high apprehension individuals results in more positive perceptions about the richness of the videoconferencing medium. While, in contrast, low apprehension individuals without recent exposure to using the technology appear to over-rate the richness of the medium.

Table 2. MANOVA tests of simple and main effects for apprehension and participation with univariate $F$-ratios of task and media characteristics

\begin{tabular}{lccc}
\hline Dependent Variables & $\begin{array}{c}\text { Apprehension } \\
\boldsymbol{F}_{(\mathbf{6}, 7 \mathbf{1})}=\mathbf{5 . 3 4 * *}\end{array}$ & $\begin{array}{c}\text { Participation } \\
\boldsymbol{F}_{(\mathbf{6}, \mathbf{7 1})}=\mathbf{1 . 4 3}\end{array}$ & $\begin{array}{c}\text { Apprehension } \\
\text { x Participation } \\
\boldsymbol{F}_{(\mathbf{6}, 7 \mathbf{1})}=\mathbf{2 . 4 7}\end{array}$ \\
\hline Conflict & 0.14 & $6.31^{*}$ & .12 \\
Meeting structure & 3.42 & 0.01 & 0 \\
Task focus & $8.52^{* *}$ & 0.55 & 0 \\
Problem complexity & $5.41^{*}$ & 0.15 & 2.48 \\
Sociability & $6.67^{*}$ & 2.47 & 1.14 \\
Communication richness & $27.46^{* *}$ & 1.43 & $9.40^{* *}$ \\
\hline
\end{tabular}

Notes: $N=80$ for the combined groups, 38 for Low Apprehension, 42 for High Apprehension

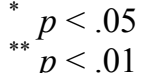

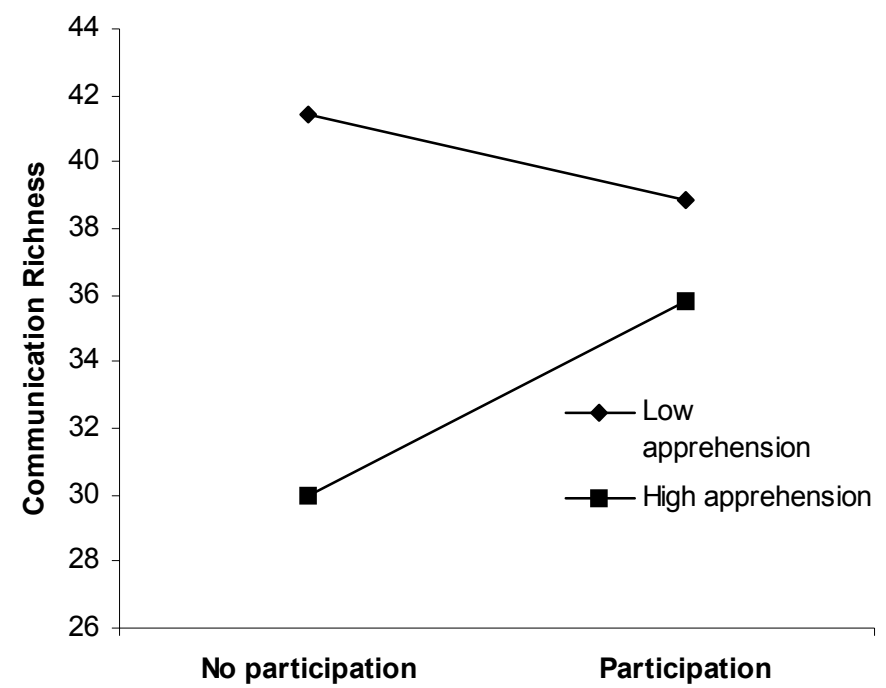

Figure 1. Mean communication richness scores for apprehension types (low and high apprehension) on level of participation during the four weeks preceding the survey 


\section{Discussion}

This study has explored the impact of communication apprehension and participation on user perceptions of task and media characteristics in a videoconferencing context. The findings indicate that the media richness and social presence aspects of media choice theory are important considerations for videoconferencing users. User aversion and discomfort during videoconferenced meetings has the potential to significantly impact on perceptions of task, processes and performance. This study provides insight into the importance of medium experience and user apprehension in organizational communication.

The findings of this study have significant consequences for practitioners and researchers in the field of organizational communication. System developers often over-emphasize the advantages of using information technology while underestimating the importance of creating systems that are easy to use and capable of supporting communication richness. In the implementation of videoconferencing systems, careful consideration should be given to developing implementation strategies that boost self-confidence and reduce user apprehension and anxiety about using the technology. These strategies must incorporate approaches beyond training programs offering only hands-on experience, and should include counseling and other constructive techniques for overcoming personal anxiety and improving communication effectiveness. '

This study used data from a single site within one organization thus significantly reducing the external validity of the findings. Despite this shortcoming, the research context did provide significant benefits. First, use of the in-house videoconferencing facility was long established in the organization and the employees had no vested interests in the success or otherwise of the technology. Second, as the study focused on one site only, the findings should not have been confounded by the existence of different social perspectives on the medium (Carlson \& Davis, 1998). Third, field research into the effects of videoconferencing technology is scarce. Nevertheless, the findings are given meaning only by organizational context and these results may not extend to all organizational settings. For example, communication apprehension and frequency of use may vary markedly for commercial corporations.

A number of measures were used in this study to measure the variables of interest. While the reliabilities of most measures were within acceptable limits, some items would benefit from further development. Future research should address ways in which videoconferencing technology can be made more compatible with the structure, culture and the overall objectives of the host organization and its users. Greater consideration should also be given to gaining a better understanding of the interaction between technological and human factors, and whether attitudes toward videoconferencing are uniformly developed across organizational boundaries and within other organizational contexts.

\section{References}

Adams, D.A., Nelson, R.R.. \& Todd, P.A. (1992). Perceived usefulness, ease of use, and usage of information technology: a replication. MIS Quarterly, 16, 227-247.

Allen, M. \& J. Bourhis. (1996). The relationship of communication apprehension to communication behavior: a meta-analysis. Communication Quarterly, 44, 214-226.

Benbasat, I. \& Lim, L. (1993). The effects of group task, context, and technology variables on the usefulness of group support systems: A Meta-Analysis. Small Group Research, 24, 30-462.

Booth-Butterfield, S. \& Cattone, R.R. (1991). Ethical issues in the treatment of communication apprehension and avoidance. Communication Education, 40, 172-179.

Brown, S.A., Fuller, R.M. \& Vician, C. (2004). Who's afraid of the virtual world? Anxiety and computermediated communication. Journal of the Association for Information Systems, 5, 79-107. 
Campbell, J. (1997). The impact of videoconferenced meetings on the pattern and structure of organizational communication. Singapore Management Review, 19, 77-93.

Campbell, J.A. (1998). Participation in videoconferenced meetings: User disposition and meeting context. Information and Management, 34, 329-338.

Carlson, P.J. \& Davis, G.B. (1998). An investigation of media selection among directors and managers: From "self" to "other" orientation. MIS Quarterly, 22, 335-362.

Daft, R.L. \& Lengel, R.H. (1984). Information richness: A new approach to managerial information processing and organizational design. In B. Straw \& L. L. Cummings (Eds.), Research in Organizational Behavior (Vol. 6, pp. 191-233). Greenwich: JAI Press.

Daft, R.L. \& Lengel, R.H. (1986). A proposed integration among organizational information requirements, media richness, and structural design. Management Science, 32, 554-571.

Davis, F.D. (1989). Perceived usefulness, perceived ease of use, and user acceptance of information technology. MIS Quarterly, 13, 319-340.

Dennis, A., George, J.F., Jessup, L.M., Nunamaker, J.F. \& Vogel, D. (1988). Information technology to support electronic meetings. MIS Quarterly, 12, 591-618.

Easton, G., Easton, A. \& Belch, M. (2003). An experimental investigation of electronic focus groups, Information and Management, 40, 717-727.

Gowan, J.A. Jr. \& Downs, J.M. (1994). Video conferencing human-machine interface. Information and Management, 27, 341-356.

Guimaraes, T. \& Dallow, P.K. (1999). Empirically testing the benefits, problems, and success factors for telecommuting programmes. European Journal of Information Systems, 8, 40-54.

Hart, P., Svenning, L. \& Ruchinskas, J. (1995). From face-to-face meeting to video teleconferencing: Potential shifts in the meeting genre. Management Communication Quarterly, 8, 395-423.

Igbaria, M. (1993). User acceptance of microcomputer technology: An empirical test. Omega, 21, 73-90.

Jaccard, J. \& Wan, C.K. (1996). LISREL approaches to interaction effects in multiple regression. Thousand Oaks, CA: Sage Publications.

Konsynski, B.R., Stohr, E.A. \& McGee, J.V. (1992). Information systems and decision processes. Los Alamitos, CA: IEEE Computer Society Press.

Kydd, C.T. \& Ferry, D.L. (1994). Managerial use of videoconferencing. Information and Management, 27, 369-375.

Lee, A.S. (1994). Electronic mail as a medium for rich communication: An empirical investigation using hermeneutic interpretation. MIS Quarterly, 18, 143-157.

Lee, D.R. \& Bohlen, G.A. (1997). Influence strategies of project managers in the information-technology industry. Engineering Management Journal, 9, 7-14.

Lucas, H.C. (1978). Empirical evidence for a descriptive model of implementation. MIS Quarterly, 2, $27-41$.

Markus, M.L. (1994). Electronic mail as the medium of managerial choice. Organization Science, 5 , 502-527.

Martinsons, M.G. \& Chong, P.K.C. (1999). The influence of human factors and specialist involvement on information systems success. Human Relations, 52, 123-152.

McCroskey, J.C. (1984). The communication apprehension perspective. In J.A. Daly \& J.C. McCroskey (Eds.), Avoiding communication: Shyness, reticence, and communication apprehension (pp. 13-38). Beverly Hills, CA: Sage Publications. 
McLeod, P. (1992). An assessment of the experimental literature on electronic support for group work: Results of a meta-analysis. Human-Computer Interaction, 7, 257-280.

McGrath, J.E. (1984). Groups: Interaction and performance. Englewood Cliffs: Prentice Hall.

McGrath, J.E. \& Hollingshead, A.B. (1993). Putting the group back in group support systems: Some theoretical issues about dynamic processes in groups with technological enhancements. In L.M. Jessup \& J.S. Valacich (Eds.), Group support systems new perspectives (pp. 78-95). New York NY: Macmillan.

McKeen, J.D. \& Smith, H.A. (1996). Management challenges in IS: Successful strategies and appropriate action. Chichester: Wiley \& Sons.

O’Connaill, B., Whittaker, S. \& Wilbur, S. (1993). Conversations over video-conferences: An evaluation of the spoken aspects of video-mediated communication. Human-Computer Interaction, 8, 389-428.

Okebukola, P.A., Sumampouw, W. \& Jegede, O.J. (1992). The experience factor in computer anxiety and interest. Journal of Educational Technology Systems, 20, 221-229.

Rao, V.S. \& Dennis, A.R. (2000) Equality of reticence in groups and idea generation: An empirical study. Journal of Information Technology Management, 11, 1-20.

Reinsch, N.L. Jr., Steele, C.M., Lewis, P.V., Stano, M. \& Beswick, R.W. (1990). Measuring telephone apprehension. Management Communication Quarterly, 4, 198-221.

Rice, R.E. \& Williams, F. (1984). Theories old and new: The study of new media. In R.E. Rice (Ed.), The new media: Communication, research and technology (pp. 55-80). Beverly Hills, CA: Sage Publications.

Richmond, V.P \& McCroskey, J.C. (1992). Communication apprehension, avoidance, and effectiveness. Scottsdale, AZ: Gorsuch Scarisbrick.

Rogers, E.M. (1986). Communication technology: The new media in society. New York, NY: The Free Press.

Rosen, L.D., Sears, D.C. \& Weil, M.M. (1993). Treating technophobia: A longitudinal evaluation of the computerphobia reduction program. Computer in Human Behavior, 9, 27-50.

Scott, C.R. \& Rockwell, S.C. (1997). The effect of communication, writing, and technology apprehension on likelihood to use new communication technologies. Communication Education, 46, 44-62.

Scott, C.R. \& Timmerman, C.E. (2005). Relating computer, communication, and computer-mediated communication apprehensions to new communication technology use in the workplace. Communication Research, 32, 683-725.

Short, J., Williams, E. \& Christie, B. (1976). The social psychology of telecommunications. London: John Wiley.

Stone, E.F. \& Stone, D.L. (1990). Privacy in organizations: Theoretical issues, research findings, and protection mechanisms. In G.R. Ferris (Ed.), Research in personnel and human resources management (Vol. 8, pp. 349-411) Greenwich: JAI Press.

Storck, J. \& Sproull, L. (1995). Through a glass darkly: What do people learn in videoconferences. Human Communication Research, 22, 197-219.

Svenning, L.L. \& Ruchinskas, J.E. (1984). Organizational teleconferencing. In R.E. Rice (Ed.), The new media: Communication, research, and technology (pp. 217-248). Beverly Hills. CA: Sage Publications.

Webster, J. (1998). Desktop videoconferencing: experiences of complete users, wary users, and non-users, MIS Quarterly, 22, 257-286.

Webster, J. \& Hackley, P. (1995). Teaching effectiveness in technology-mediated distance learning. Academy of Management Journal, 40, 1282-1309. 
Webster, J. \& Trevino, L.K. (1995). Rational and social theories as complimentary explanations of communication media. Academy of Management Journal, 38, 1544-1572.

Weil, M.M., Rosen, L.D. \& Wugalter, S.E. (1990). The etiology of computerphobia. Computers in Human Behavior, 6, 361-379.

Williams, E. (1978). Teleconferencing: social and psychological factors. Journal of Communication, 28, $125-131$

Zmud, R.W. (1979). Individual differences and MIS success: a review of the empirical literature. Management Science, 25, 966-979.

\section{Biography}

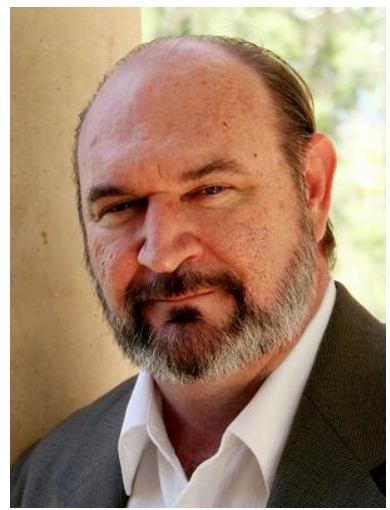

John Campbell is Associate Professor of Information Systems, School of Information Sciences and Engineering, University of Canberra, Australia. His research expertise includes topics in information security, IT governance, IT investment evaluation, virtual communities, and organizational communication. A major theme throughout his work is how users interact through information systems in the social world and, in particular, the ways in which organizational decision-making and community interaction are enacted through collaborative technologies. 